\title{
Autosomal recessive spastic paraplegia type 32
}

INSERM

\section{Source}

INSERM. (1999). Orphanet: an online rare disease and orphan drug data base. Autosomal recessive spastic paraplegia type 32. ORPHA:171622

Autosomal recessive spastic paraplegia type 32 (SPG32) is a rare, complex type of hereditary spastic paraplegia characterized by a slowly progressive spastic paraplegia (with walking difficulties appearing at onset at 6-7 years of age) associated with mild intellectual disability. Brain imaging reveals thin corpus callosum, cortical and cerebellar atrophy, and pontine dysraphia. The SPG32 phenotype has been mapped to a locus on chromosome 14q12-q21. 